\title{
Prognosis and treatment results of patients with atrial arrhythmia and thrombus or dense spontaneous echo contrast in left atrial appendage
}

\section{Katarzyna Kosmalska ( $\sim$ katarzyn5@wp.pl)}

Centre Hospitalier Universitaire de Charleroi - Hopital Vincent van Gogh https://orcid.org/0000-00017132-8116

\section{Malgorzata Rzyman}

St. Vincent Hospital

\section{Ludmila Danilowicz-Szymanowicz}

Department of Cardiology and Electrotherapy, Medical University of Gdańsk

\section{Marcin Fijałkowski}

First Department of Cardiology, Medical University of Gdańsk

\section{Research}

Keywords: Left atrial appendage, thrombus, slugde, atrial fibrillation, anticoagulation

Posted Date: June 8th, 2020

DOl: https://doi.org/10.21203/rs.3.rs-33055/v1

License: (9) This work is licensed under a Creative Commons Attribution 4.0 International License. Read Full License 


\section{Abstract}

Introduction. Thrombus or sludge in the left atrial appendage (LAA) are both absolute contraindications for cardioversion; however, further therapeutic guidance has not been discovered.

Objectives. This study focused on assessing these patients' risk, the effectiveness of anticoagulation in thrombus resolution, and the treatment influence on patients' risk. Patients and methods. Seventysevenout of $267(29 \%)$ patients with arrhythmia who were scheduled for cardioversion were diagnosed with thrombus or sludge. Of these, $44 \%$ had chronic arrhythmia and were prescribed an oral anticoagulant; the other $56 \%$ underwent further attempts at cardioversion. The entire sample was analyzed for annual risk of death and stroke in termsof anticoagulation and thrombus resolution. The effectiveness of anticoagulants was also assessed. Finally, sludge was compared to thrombus.

Results. The annual mortality in patients with thrombus or sludge was $23 \%$. In the group without thrombus,annual mortality was $1.6 \%$. A total of $17 \%$ of patients with thrombus or sludge experienced ischemic stroke. In patients without thrombus, their risk of stroke was $1 \%$. Heparin performed better for thrombus resolution (82\%) compared to non-vitamin-K-OAC(44\%) and vitamin-K antagonists (43\%). Sludge increased mortality and risk of stroke comparedto those without thrombus or sludge LAA: $16 \%$ vs. $1.5 \%$ and $11 \%$ vs. $1 \%$, respectively.Comparison between sludge and thrombus did not reveal differences. This study failed to find a prognosis-improving treatment.

Conclusions. Thrombus or sludge in the LAA have a poor pronosis. Heparin is better than oral anticoagulation for dissolving thrombus. None of the analyzed treatment methods significantly decreased the risk of death or stroke.

\section{Background}

Atrial fibrillation (AF) and atrial flutter (AFL) are the most frequent sustained cardiac arrhythmias, with a prevalence of about $2-3 \%$ in the general population; they have a $10 \%$ annual risk of death $[1,2,3]$. AF/AFL is associated with the development of left atrial appendage (LAA) thrombus, which is the main source of stroke and systemic embolism $[4,5,6,7]$.

Several studies have stated that transoesophageal echocardiography (TOE) is a conclusive imaging technique for excluding or confirming thrombus or dense spontaneous echo contrast in the LAA $[8,9,10]$. In subjects with atrial fibrillation, the thrombus in the LAA as well as dense spontaneous echo contrast (sludge) have been recognized as a robust independent risk factor for stroke [11, 12]. Another recognized neurological complication are cognitive disorders: patients with thrombus or sludge in LAA had achieved significantly lower results in Mini Mental State Examination (MMSE) than patients free from the findings [13] An established method for decreasing the risk of potentially fatal thromboembolism in AF/AFL is anticoagulation $[11,14,15]$. However, many patients are still diagnosed with thrombus or dense spontaneous echocontrast in the LAA despite proper anticoagulation $[13,16,17,18]$. There is no specific guidance on how to proceed with patients diagnosed with thrombus or sludge in the LAA. There are no 
recommendations to perform routine TOE control for assessing thrombus resolution, and the decision to perform control TOE is usually made by the physician and the patient when the AF/AFL is persistent but not chronic. Usually, in our two centers only the persistent AF/AFI yields TOE control for further cardioversion enabling.

It is not only target cardioversion that indicates a thrombus is dissolving. Many procedures of planned AF/AFL ablation or percutaneous LAA closure must be postponed or even cancelled due to the presence of an LAA thrombus. For these reasons, it is necessary to discover an effective method of thrombus resolution.

This study aimed to answer the following relevant clinical questions: (i) How high is the risk of ischemic stroke and death in patients with diagnosed thrombus or sludge in LAA? (ii) Is sludge equally dangerous as solid thrombus? (iii)What kind of anticoagulation is the most effective in thrombus resolution? (iv) Is there a particular treatment method that decreases risk of death and stroke?

\section{Methods}

From January 2016 to June 2017, 267 consecutive patients from two medical centers (St. Vincent Hospital in Gdynia and the First Department of Cardiology, Medical University of Gdansk) who were scheduled for direct current cardioversion (DCC) due to persistent AF/AFL were prospectively enrolled in the study. The exclusion criteria were arrhythmia shorter than $48 \mathrm{~h}$, contraindications to TOE, and lack of consent. All the included patients had undergone transthoracic and transesophageal echocardiography. The local ethics committee approved the study protocol, and written informed consent was obtained from all participants.

Ultrasound scanners (GE, Vivid S70, Horten, Norway) equipped with a 1.5-4.6 MHz transducer and a 3$8 \mathrm{MHz}$ omniplane phase probe were used. In transesophageal echocardiography, precise scanning of the LAA was performed at angles $30^{\circ} / 60^{\circ} / 90^{\circ} / 120^{\circ}$; transgastric two-chamber was performed at an angle of $90^{\circ}$, with careful adjustment of the gain and frequency in search of thrombus and dense spontaneous echo-contrast (sludge) $[19,20,21]$. LAA early diastolic emptying velocity was also measured. As described in the literature, sludge was defined as an intracavitary echo-density with viscid gelatinous qualities that gave the impression of impending precipitation but without a discrete organized mass [22, 23]. Echocardiography was performed and analyzed by two certified echocardiographers (researchers KK and MF) with appropriate intra- and interobserver reproducibility. In the case of confirming both LAA thrombus and sludge, sinus rhythm reversal was postponed. Further therapeutic decisions depended on clinical conditions: 34 patients (44\%) had chronic atrial fibrillation; they were prescribed standard OAC therapy and no TOE control. The remaining 43 patients (56\%) underwent further attempts at cardioversion in the case of thrombus resolution with the use of three different methods of anticoagulation: vitamin-K- antagosists (VKA) with rigorous control of INR, non-vitamin-K oral anticoagulants (NOAC) in recommended for AF/AFI doses or therapeutic doses of low molecular weight heparin (LMWH): enoxaparin $1 \mathrm{mg} / \mathrm{kg}$ bid. The latter group was subjected to control TOE three months 
later. The study followed up with the patients with and without thrombus or sludge for one year to evaluate deaths and thromboembolic events. (Fig. 1) The main follow-up data source was a telephone survey. In the case of futile phone contact, the patients' general practitioners or the national healthcare system were queried.

\section{STATISTICAL ANALYSIS}

The data are presented as mean \pm standard deviation, percentages, or medians with interquartile ranges. The clinical characteristics between the study groups were compared by independent sample t-tests, the Mann-Whitney $\mathrm{U}$ test for continuous variables, and the Fisher's exact test for categorical variables. To compare the risk of stroke and death in the two analyzed groups, a Fisher's exact test was used. Comparison of proportion test was applied to assess anticoagulation effectiveness. Computations were performed using Statistica version 13.1. A p-value $<.05$ was considered to be statistically significant.

\section{Results}

In the whole group of 267 patients, 77 (29\%) were diagnosed with thrombus or sludge. The baseline characteristics of patients with and without LAA thrombus or sludge are shown in Table 1. Among the group with thrombus or sludge in LAA, $9 \%$ were not adequately treated with anticoagulants before TOE (either no anticoagulation or anticoagulation shorter than 3 weeks or warfarin with TTR $<80 \%$ or LMWH in prophylactic dose), $3 \%$ received therapeutic doses of $\mathrm{LMWH}, 54 \%$ received NOAC, and $34 \%$ received VKA. In Additional Table 3 we have presented characteristics of patients subjected to further TOE control. Additional Table 3shows no significant differences in baseline characteristics between patients who succeeded or failed in thrombus resolution. 
Table 1

Baseline characteristics of patients with and without thrombus or sludge

\begin{tabular}{|c|c|c|c|}
\hline & $\begin{array}{l}\text { Thrombus or } \\
\text { sludge }(+) \mathrm{N}= \\
77\end{array}$ & $\begin{array}{l}\text { Thrombus or } \\
\text { sludge }(-) \mathrm{N}= \\
190\end{array}$ & $\begin{array}{l}\text { p- } \\
\text { value }\end{array}$ \\
\hline \multicolumn{4}{|l|}{ Clinical } \\
\hline Age /mean & $74.99 \pm 8.17$ & $73.01 \pm 10.19$ & 1.000 \\
\hline Female sex / number of patients (percentage) & $42(54.54)$ & $82(43.16)$ & 0.092 \\
\hline CHA2DS2VASc / mean & $\begin{array}{l}4.70(4.00- \\
6.00)\end{array}$ & $4.00(3.00-5.00)$ & 0.101 \\
\hline $\begin{array}{l}\text { CHA2DS2VASc }>3 \text { / number of patients } \\
\text { (percentage) }\end{array}$ & $61(79.22)$ & $138(72.63)$ & 0.264 \\
\hline $\begin{array}{l}\text { First episode of AF/AFI/ number of patients } \\
\text { (percentage) }\end{array}$ & $23(29.87)$ & $92(48.42)$ & 0.006 \\
\hline Atrial flutter / number of patients (percentage) & $12(15.58)$ & $41(21.58)$ & 0.267 \\
\hline Arrhythmia episode duration in weeks / mean & $53.91 \pm 108.23$ & $22.53 \pm 40.99$ & 0.011 \\
\hline BMI $(\mathrm{kg} / \mathrm{m} 2) /$ mean & $29.06 \pm 5.35$ & $29.11 \pm 4.94$ & 0.942 \\
\hline Overweight / number of patients (percentage) & $31(40.26)$ & $79(41.58)$ & 0.843 \\
\hline Obesity / number of patients (percentage) & $29(37.66)$ & $69(36.32)$ & 0.837 \\
\hline $\begin{array}{l}\text { Arterial hypertension / number of patients } \\
\text { (percentage) }\end{array}$ & $63(81.82)$ & $147(77.37)$ & 0.422 \\
\hline Diabetes / number of patients (percentage) & $35(45.45)$ & $68(35.79)$ & 0.142 \\
\hline $\begin{array}{l}\text { Previous stroke/TIA / number of patients } \\
\text { (percentage) }\end{array}$ & $17(22.08)$ & $42(22.11)$ & 0.996 \\
\hline $\begin{array}{l}\text { Vascular disease / number of patients } \\
\text { (percentage) }\end{array}$ & $49(63.64)$ & $100(52.63)$ & 0.102 \\
\hline $\begin{array}{l}\text { Congestive heart failure / number of patients } \\
\text { (percentage) }\end{array}$ & $39(50.65)$ & $72(37.89)$ & 0.056 \\
\hline Active cancer / number of patients (percentage) & $2(2.60)$ & $7(3.68)$ & 0.656 \\
\hline $\begin{array}{l}\text { Cancer in medical history / number of patients } \\
\text { (percentage) }\end{array}$ & $6(7.79)$ & $16(8.42)$ & 0.866 \\
\hline Smoking / number of patients (percentage) & $4(5.19)$ & $7(3.68)$ & 0.574 \\
\hline $\begin{array}{l}\text { Active inflammation / number of patients } \\
\text { (percentage) }\end{array}$ & $5(6.49)$ & $14(7.37)$ & 0.802 \\
\hline $\begin{array}{l}\text { Infection in last } 3 \text { months / number of patients } \\
\text { (percentage) }\end{array}$ & $16(20.78)$ & $33(17.37)$ & 0.515 \\
\hline
\end{tabular}

Clinical

\begin{tabular}{|c|c|c|c|}
\hline & $\begin{array}{l}\text { Thrombus or } \\
\text { sludge }(+) \mathrm{N}= \\
77\end{array}$ & $\begin{array}{l}\text { Thrombus or } \\
\text { sludge }(-) \mathrm{N}= \\
190\end{array}$ & $\begin{array}{l}\text { p- } \\
\text { value }\end{array}$ \\
\hline \multicolumn{4}{|l|}{ Clinical } \\
\hline Age /mean & $74.99 \pm 8.17$ & $73.01 \pm 10.19$ & 1.000 \\
\hline Female sex / number of patients (percentage) & $42(54.54)$ & $82(43.16)$ & 0.092 \\
\hline CHA2DS2VASc / mean & $\begin{array}{l}4.70(4.00- \\
6.00)\end{array}$ & $4.00(3.00-5.00)$ & 0.101 \\
\hline $\begin{array}{l}\text { CHA2DS2VASc }>3 \text { / number of patients } \\
\text { (percentage) }\end{array}$ & $61(79.22)$ & $138(72.63)$ & 0.264 \\
\hline $\begin{array}{l}\text { First episode of AF/AFI/ number of patients } \\
\text { (percentage) }\end{array}$ & $23(29.87)$ & $92(48.42)$ & 0.006 \\
\hline Atrial flutter / number of patients (percentage) & $12(15.58)$ & $41(21.58)$ & 0.267 \\
\hline Arrhythmia episode duration in weeks / mean & $53.91 \pm 108.23$ & $22.53 \pm 40.99$ & 0.011 \\
\hline BMI $(\mathrm{kg} / \mathrm{m} 2) /$ mean & $29.06 \pm 5.35$ & $29.11 \pm 4.94$ & 0.942 \\
\hline Overweight / number of patients (percentage) & $31(40.26)$ & $79(41.58)$ & 0.843 \\
\hline Obesity / number of patients (percentage) & $29(37.66)$ & $69(36.32)$ & 0.837 \\
\hline $\begin{array}{l}\text { Arterial hypertension / number of patients } \\
\text { (percentage) }\end{array}$ & $63(81.82)$ & $147(77.37)$ & 0.422 \\
\hline Diabetes / number of patients (percentage) & $35(45.45)$ & $68(35.79)$ & 0.142 \\
\hline $\begin{array}{l}\text { Previous stroke/TIA / number of patients } \\
\text { (percentage) }\end{array}$ & $17(22.08)$ & $42(22.11)$ & 0.996 \\
\hline $\begin{array}{l}\text { Vascular disease / number of patients } \\
\text { (percentage) }\end{array}$ & $49(63.64)$ & $100(52.63)$ & 0.102 \\
\hline $\begin{array}{l}\text { Congestive heart failure / number of patients } \\
\text { (percentage) }\end{array}$ & $39(50.65)$ & $72(37.89)$ & 0.056 \\
\hline Active cancer / number of patients (percentage) & $2(2.60)$ & $7(3.68)$ & 0.656 \\
\hline $\begin{array}{l}\text { Cancer in medical history / number of patients } \\
\text { (percentage) }\end{array}$ & $6(7.79)$ & $16(8.42)$ & 0.866 \\
\hline Smoking / number of patients (percentage) & $4(5.19)$ & $7(3.68)$ & 0.574 \\
\hline $\begin{array}{l}\text { Active inflammation / number of patients } \\
\text { (percentage) }\end{array}$ & $5(6.49)$ & $14(7.37)$ & 0.802 \\
\hline $\begin{array}{l}\text { Infection in last } 3 \text { months / number of patients } \\
\text { (percentage) }\end{array}$ & $16(20.78)$ & $33(17.37)$ & 0.515 \\
\hline
\end{tabular}

Thrombus or sludge $(-) \mathrm{N}=$ 190

pvalue 


\begin{tabular}{|c|c|c|c|}
\hline & $\begin{array}{l}\text { Thrombus or } \\
\text { sludge (+) N = } \\
77\end{array}$ & $\begin{array}{l}\text { Thrombus or } \\
\text { sludge }(-) \mathrm{N}= \\
190\end{array}$ & $\begin{array}{l}\mathrm{p}- \\
\text { value }\end{array}$ \\
\hline $\begin{array}{l}\text { Surgery in last } 3 \text { months / number of patients } \\
\text { (percentage) }\end{array}$ & $4(5.19)$ & $12(6.32)$ & 0.727 \\
\hline \multicolumn{4}{|l|}{ Echocardiography } \\
\hline LVEF / mean & $43.36 \pm 12.48$ & $46.24 \pm 11.72$ & 0.075 \\
\hline LA area/ mean & $30.18 \pm 10.26$ & $27.05 \pm 5.22$ & 1.000 \\
\hline $\begin{array}{l}\text { Presence of spontaneous echo contrast / number } \\
\text { of patients (percentage) }\end{array}$ & $56(72.73)$ & $62(32.63)$ & $<0001$ \\
\hline $\begin{array}{l}\text { Low LAA velocities / number of patients } \\
\text { (percentage) }\end{array}$ & $68(88.31)$ & $113(59.47)$ & $<.0001$ \\
\hline $\begin{array}{l}\text { Aortic stenosis moderate-to-severe / number of } \\
\text { patients (percentage) }\end{array}$ & $4(5.19)$ & $13(6.84)$ & 0.618 \\
\hline $\begin{array}{l}\text { Aortic regurgitationmoderate-to-severe / number of } \\
\text { patients (percentage) }\end{array}$ & $2(2.60)$ & $6(3.16)$ & 0.808 \\
\hline $\begin{array}{l}\text { Mitral stenosis moderate-to-severe / number of } \\
\text { patients (percentage) }\end{array}$ & $3(3.90)$ & $1(0.53)$ & 0.040 \\
\hline $\begin{array}{l}\text { Mitral regurgitation moderate-to-severe / number } \\
\text { of patients (percentage) }\end{array}$ & 18 (23.38) & $50(26.32)$ & 0.618 \\
\hline $\begin{array}{l}\text { Aortic prosthesis / number of patients } \\
\text { (percentage) }\end{array}$ & $4(5.19)$ & $8(4.21)$ & 0.726 \\
\hline $\begin{array}{l}\text { Mitral prosthesis / number of patients } \\
\text { (percentage) }\end{array}$ & $4(5.19)$ & $5(2.63)$ & 0.294 \\
\hline \multicolumn{4}{|l|}{ Laboratory } \\
\hline Creatinine mean (mg/dl) & $0.99 \pm 0.38$ & $1.01 \pm 0.41$ & 0.713 \\
\hline Haematocrit mean (\%) & $40.46 \pm 4.54$ & $40.63 \pm 4.68$ & 0.787 \\
\hline Platelets mean (G/I) & $213.19 \pm 54.87$ & $220.07 \pm 82.79$ & 0.503 \\
\hline INR mean & $1.90 \pm 0.89$ & $1.73 \pm 0.72$ & 1.000 \\
\hline aPTT ratio mean & $1.34 \pm 0.40$ & $1.30 \pm 0.33$ & 1.000 \\
\hline \multicolumn{4}{|l|}{ Anticoagulation } \\
\hline Anticoagulation / number of patients (percentage) & $70(90.91)$ & $168(88.42)$ & 0.555 \\
\hline Anticoagulation duration in weeks / mean & $111.73 \pm 201.73$ & $123.05 \pm 235.11$ & 0.711 \\
\hline $\begin{array}{l}\text { Anticoagulation }>4 \text { weeks / number of patients } \\
\text { (percentage) }\end{array}$ & $66(85.71)$ & $159(83.68)$ & 0.680 \\
\hline
\end{tabular}




\begin{tabular}{|c|c|c|c|}
\hline & $\begin{array}{l}\text { Thrombus or } \\
\text { sludge (+) N = } \\
77\end{array}$ & $\begin{array}{l}\text { Thrombus or } \\
\text { sludge }(-) \mathrm{N}= \\
190\end{array}$ & $\begin{array}{l}\mathrm{p}- \\
\text { value }\end{array}$ \\
\hline NOAC / number of patients (percentage) & $37(48.05)$ & $122(64.21)$ & 0.015 \\
\hline $\begin{array}{l}\text { Vitamin } \mathrm{K} \text { antagonists with TTR }>85 \% \text { / number of } \\
\text { patients (percentage) }\end{array}$ & $29(37.66)$ & $43(22.63)$ & 0.012 \\
\hline $\begin{array}{l}\text { No anticoagulation or shorter than } 3 \text { weeks or } \\
\text { warfarin with TTR }<80 \% \text { or LMWH in prophylactic } \\
\text { dose / number of patients (percentage) }\end{array}$ & $7(9.09)$ & $20(12.35)$ & 0.725 \\
\hline $\begin{array}{l}\text { Anticoagulation interruption in last three months / } \\
\text { number of patients (percentage) }\end{array}$ & $12(15.58)$ & $11(5.79)$ & 0.01 \\
\hline $\begin{array}{l}\text { Cardiologist-controlled anticoagulation / number } \\
\text { of patients (percentage) }\end{array}$ & 41/59 (69.49) & 100/143 (69.93) & 0.951 \\
\hline \multicolumn{4}{|l|}{ Mini Mental State Examination } \\
\hline MMSE score / mean & $24.80 \pm 4.30$ & $26.62 \pm 3.38$ & $\begin{array}{l}< \\
0.001\end{array}$ \\
\hline $\begin{array}{l}\text { Mild impairment of congnitive function / number } \\
\text { of patients (percentage) }\end{array}$ & $16(20.78)$ & 30 (15.79) & 0.329 \\
\hline Dementia / number of patients (percentage) & $6(7.79)$ & $2(1.05)$ & 0.0035 \\
\hline
\end{tabular}

Table 2

The comparison of ischaemic strokes and mortality in thrombus or sludge vs no thrombus nor sludge (Fisher)

\begin{tabular}{|c|c|c|c|}
\hline & Thrombus/Sludge (+) & Thrombus/Sludge (-) & $n$ \\
\hline Ischemic stroke event (\%) & $13(17 \%)$ & $2(1 \%)$ & 15 \\
\hline No ischemic stroke event (\%) & $64(83 \%)$ & $188(99 \%)$ & 252 \\
\hline $\mathbf{n}$ & 77 & 190 & Total 267 \\
\hline \multicolumn{4}{|l|}{ Test Fisher exact $p<0.001$} \\
\hline One-year mortality (\%) & $18(23 \%)$ & $3(1.6 \%)$ & 21 \\
\hline One-year survivors (\%) & $59(77 \%)$ & $187(98.4 \%)$ & 246 \\
\hline $\mathbf{n}$ & 77 & 190 & Total 267 \\
\hline
\end{tabular}


Table 3

The comparison of ischaemic strokes and mortality in sludge vs no thrombus nor sludge (Fisher)

\begin{tabular}{|llll|}
\hline & Sludge (+) & No Thrombus/Sludge & $\mathbf{n}$ \\
\hline Ischemic stroke event (\%) & $2(11 \%)$ & $2(1 \%)$ & 4 \\
\hline No ischemic stroke event (\%) & $17(89 \%)$ & $188(99 \%)$ & 205 \\
\hline $\mathbf{n}$ & 19 & 190 & Total 209 \\
\hline Test Fisher exact $p<0.042$ & & & 6 \\
\hline One-year mortality (\%) & $2(11 \%)$ & $3(1.6 \%)$ & 203 \\
\hline One-year survivors (\%) & $17(89 \%)$ & $187(98.3 \%)$ & Total 209 \\
\hline $\mathbf{n}$ & 19 & 190 & \\
\hline Test Fisher exact $p<0.066$ & & & \\
\hline
\end{tabular}

\section{Risk of ischemic stroke and annual mortality}

After a one-year follow-up with the thrombus or sludge group, 18 patients had died (23\%) and $13(17 \%)$ had experienced ischemic stroke. In the group without thrombus or sludge, three patients (1.6\%) had died and two (1\%) had experienced non-fatal ischemic stroke(Table 2). The odds ratio (OR) for mortality was 19.01 (95\% confidence interval [Cl]: 5.4-66.8, p < 0.0001). The relative risk RR for mortality was $3.6(95 \%$ Cl: 2.7-4.7, $\mathrm{p}<0.0001)$. The OR for ischemic stroke was 19.1 (95\% Cl: 4.2-86.9, p<0.0001). The RR for ischemic stroke was $3.4(95 \% \mathrm{Cl} 2.5-4.6, \mathrm{p}<0.0001)$. The $\mathrm{OR}$ for both mortality and ischemic stroke was 24.9 (95\% Cl: 9.2-67.7, p<0.0001). Finally, the RR for both mortality and ischemic stroke was $4.3(95 \%$ Cl: $3.2-5.8, p<0.0001)$.

\section{Effectiveness of thrombus or sludge resolution in not- anticoagulated patients (Fig. 1)}

Seven patients $(9 \%)$ had not been previously treated with anticoagulants or had been treated inadequately. The group demonstrated high effectiveness of oral anticoagulants ( 5 patients were treated with NOAC, 2 patients with VKA)-in all of the patients subjected to control TOE, there were no instances of thrombus or sludge. Anticoagulant LMWH turned out to be the most effective treatment in thrombus or sludge resolution in the group of patients previously treated with OAC ( 9 out of 11 patients, $82 \%$ ). NOACs and VKA had similar outcomes (NOACs: 8 out of 18 patients, 44\%; VKA: 3 out of 7 patients, $43 \%$ ), but their effectiveness was significantly lower than that of LMWH $(p<0.035)$. The number needed to treat to resolve thrombus or sludge LAA was 2.6 (95\% Cl: $1.4-20.7, p=0.09)$.

Differences in risk of ischemic stroke and annual mortality between sludge vs. appendage free from thrombus or sludge 
After a one-year follow-up with the group containing sludge patients, two patients had died $(11 \%)$ and three $(16 \%)$ had experienced ischemic stroke. In the group without thrombus or sludge, three patients had died $(1.6 \%)$ and two (1\%) had experienced ischemic stroke The statistical differences are significant in terms of stroke or borderline for 1-year mortality but based on small number of events so analysis and conclusions should be careful(Table 3).

\section{No significant differences in risk of ischemic stroke and annual mortality between thrombus and sludge}

Patients with sludge in the LAA experienced fewer strokes (2 out of $19,11 \%$ ) than those with thrombus (9 out of $58,16 \%$ ). There were also fewer deaths in patients with sludge ( 3 out of $19,16 \%$ ) than in patients with thrombus ( 14 out of $58,24 \%$ ), but the differences were not statistically significant (Table 4 )

Table 4

The comparison of ischaemic strokes and mortality in sludge vs thrombus (Fisher)

\begin{tabular}{|llll|}
\hline & Sludge & Thrombus & $\mathbf{n}$ \\
\hline Ischemic stroke event (\%) & $2(11 \%)$ & $9(16 \%)$ & 11 \\
\hline No ischemic stroke event (\%) & $17(89 \%)$ & $49(84 \%)$ & 66 \\
\hline $\mathbf{n}$ & 19 & 58 & Total 77 \\
\hline Test Fisher exact $p<0.722$ & & & \\
\hline One-year mortality (\%) & $3(16 \%)$ & $14(24 \%)$ & 17 \\
\hline One-year survivors (\%) & $16(84 \%)$ & $44(76 \%)$ & 60 \\
\hline $\mathbf{n}$ & 19 & 58 & Total 77 \\
\hline Test Fisher exact $p<0.539$ & & & \\
\hline
\end{tabular}

\section{No significant differences in risk level between successful and unsuccessful thrombus/sludge resolution}

Patients with dissolved thrombus or sludge in the LAA experienced fewer ischemic strokes (2 out of $26.8 \%$ ) than those with persistent thrombus/sludge ( 2 out of $16 ; 12 \%$ ). There were fewer deaths among patients with dissolved thrombus or sludge (4 out of $26 ; 15 \%$ ) than among patients with persistent thrombus or sludge (4 out of $16 ; 25 \%$ ), but the differences were not statistically significant (Table 5 ). 
Table 5

The comparison of ischaemic strokes and mortality between patients with and without thrombus resolution (Fisher)

\begin{tabular}{|llll|}
\hline & Thrombus resolution (+) & Thrombus resolution $(-)$ & $\mathbf{n}$ \\
\hline Ischemic stroke event (\%) & $2(8 \%)$ & $2(12 \%)$ & 4 \\
\hline No ischemic stroke event (\%) & $24(92 \%)$ & $14(88 \%)$ & 38 \\
\hline $\mathbf{n}$ & 26 & 16 & Total 42 \\
\hline Test Fisher exact $p<0.628$ & & & 8 \\
\hline One-year mortality (\%) & $4(15 \%)$ & $4(25 \%)$ & 34 \\
\hline One-year survivors $(\%)$ & $22(85 \%)$ & $12(75 \%)$ & Total 42 \\
\hline $\mathbf{n}$ & 26 & 16 & \\
\hline Test Fisher exact $p<0.454$ & & & \\
\hline
\end{tabular}

No significant differences in risk level between patients subjected to TOE control vs. those without further TOE control

After diagnosis of LAA thrombus, 34 patients (44\%) were diagnosed with chronic arrhythmia and prescribed standard OAC. The TOE control was abandoned in this group. The remaining 43 patients (56\%) underwent anticoagulation to dissolve thrombus. The latter group was subjected to further TOE control and directed to undergo cardioversion in the case of thrombus resolution. Patients with thrombus or sludge had fewer strokes (4 out of $43 ; 9 \%$ ) and deaths (7 out of $43 ; 16 \%$ ) if they were further treated with thrombus resolution and cardioversion. Patients who decided against further control and cardioversion had a higher number of strokes ( 7 out of $34 ; 21 \%$ ) and deaths ( 10 out of $34 ; 29 \%$ ), but the differences were not significant (Table 6). 
Table 6

The comparison of ischaemic strokes and mortality between patients subjected to TOE control versus those without further TOE control (Fisher)

\begin{tabular}{|llll|}
\hline & $\begin{array}{l}\text { TOE control (+) } \\
\text { Intension for thrombus resolution }\end{array}$ & TOE control (-) & $\mathbf{n}$ \\
\hline Ischemic stroke event (\%) & $4(9 \%)$ & $7(21 \%)$ & 11 \\
\hline No ischemic stroke event (\%) & $39(91 \%)$ & $27(79 \%)$ & 66 \\
\hline $\mathbf{n}$ & 43 & 34 & Total 77 \\
\hline Test Fisher exact $p<0.198$ & & & 17 \\
\hline One-year mortality $(\%)$ & $7(16 \%)$ & $10(29 \%)$ & 60 \\
\hline One-year survivors $(\%)$ & $36(84 \%)$ & $24(71 \%)$ & Total 77 \\
\hline $\mathbf{n}$ & 43 & 34 & \\
\hline Test Fisher exact $p<0.181$ & & & \\
\hline
\end{tabular}

\section{No significant differences in risk level between patients treated with LMWH vs. OAC}

Patients treated with LMWH had a lower risk of stroke (1 out of 12; $9 \%$ ) than those treated with OAC (12 out of $16 ; 19 \%$ ). The number of deaths in patients treated with LMWH ( 2 out of $12 ; 19 \%$ ) was also lower than the number of deaths in the OAC group (16 out of $63 ; 25 \%$ ). Neither of these differences were statistically significant (Table 7).

Table 7

The comparison of ischaemic strokes and mortality in persistent AF or AFI between LMWH and OAC (Fisher)

\begin{tabular}{|llll|}
\hline & LMWH & OAC & $\mathbf{n}$ \\
\hline Ischemic stroke event (\%) & $1(9 \%)$ & $4(13 \%)$ & 5 \\
\hline No ischemic stroke event (\%) & $10(91 \%)$ & $27(87 \%)$ & 37 \\
\hline $\mathbf{n}$ & 11 & 31 & Total 42 \\
\hline Test Fisher exact $p<1.0$ & & & \\
\hline One-year mortality (\%) & $2(18 \%)$ & $5(16 \%)$ & 7 \\
\hline One-year survivors (\%) & $9(82 \%)$ & $26(84 \%)$ & 37 \\
\hline $\mathbf{n}$ & 11 & 31 & Total 42 \\
\hline Test Fisher exact $p<1.0$ & & & \\
\hline
\end{tabular}




\section{Discussion}

Administering transoesophageal echocardiography before cardioversion has revealed a major problem: atrial thrombus in atrial arrhythmia $[3,13,25]$. Despite often-present potentially devastating atrial thrombus, there are no guidelines on how to treat these patients to decrease their risk of stroke and death. The problem of how to deal with a patient diagnosed with thrombus in the LAA is still unresolved. This uncertainty led the present study to conduct further observations of patients with AF/AFL who underwent TOE before planned cardioversion [13] with respect to the main endpoints (strokes and deaths). It is worth mentioning that the annual mortality among patients from developed countries who have atrial fibrillation is approximately $10 \%[1,2,3]$. The present study results revealed that the risk of this outcome was $23 \%$ among patients with thrombus or sludge; this is compared to only $1.6 \%$ in patients with an LAA free from these complications. This analysis revealed a very high annual risk of ischemic stroke in thrombus and sludge patients: $17 \%$ vs. $1 \%$ in patients without thrombus/sludge. The annual ischemic stroke risk in the general population of AF/AFL (for anticoagulated patients) is $1.4 \%$ for NOACs and $1.7 \%$ for VKA $[1,2,3]$. Thrombus or sludge in the LAA comes with a poor prognosis in terms of death and ischemic stroke. Therefore, the question of how to treat these patients is of great clinical value. Oral anticoagulants have high effectiveness in patients who have not previously been treated. This study found that implementing heparin for three months was the most effective therapeutic option (continuing OAC resulted dissolving thrombus in $44 \%$ vs. $82 \%$ with $L M W H$ treatment). A similar efficacy of OAC $(41.5 \%)$ was revealed in a CLOT-AF study [26].

Another problem was how to classify patients with dense spontaneous echocontrast (sludge). In this study, the presence of sludge increased the risk of ischemic stroke (significantly) and probably also death (without statistical significance) compared to LAA free from thrombus or sludge. Moreover, there was no statistically significant difference in the number of strokes or deaths between patients with a diagnosis of sludge vs thrombus. Our results are similar to published previously by Fatkin et al. [23] and Berhardt et al. [24]. Paradoxically, these poor results yield easier clinical decisions, as differentiation between sludge and thrombus is often difficult $[22,23]$.

Despite our expectations, dissolving LAA thrombus or sludge did not significantly decrease the risk of ischemic stroke or death. Considering the high effectiveness of heparin, this study expected an improved prognosis during LMWH therapy. There was a lower number of deaths and strokes on heparin therapy vs OAC,but the differences not statistically significant.

The encouraging results of the present pilot study need to be confirmed in further analyses based on bigger groups of patients and - in case of positive verification - this might be helpful in decision making how to treat patients with LAA thrombus or sludge diagnosis

\section{Limitations}


This study has several limitations. It did not establish how long anticoagulation should be administered for thrombus resolution. This study chose an arbitrary period of three months, but there is a lack of safety data for such a long treatment. It is also unclear whether hemorrhagic complications or increased mobility of unloosed thrombus in the group of very intensively anticoagulated patients could have impacted the results. The groups of patients from the two centers were relatively small, which may partly explain the lack of statistical significance. Both departments are participate in a new Polish multicenter prospective registry called Left Atrial Thrombus on TEE (LATEE). This study hopes that analyzing the larger groups of patients contained in this registry will answer some of the still- open clinical questions [27].

\section{Conclusions}

Diagnosis of thrombus or sludge in the left atrium in patients with atrial arrhythmias not only excludes the reversal of sinus rhythm but is also an important poor prognostic factor. The risk of death or ischemic stroke between thrombus and sludge in the LAA is similar. LMWH seems to be more effective than oral anticoagulation in thrombus resolution. Resolving thrombus or sludge yields fewer deaths and strokes in comparison to persistent thrombus or sludge, but the differences are not statistically significant..

\section{Abbreviations}

LAA - left atrial appendage; AF - atrial fibrillation; AFI - atrial flutter; TOE - transoesophagal echocardiography; DCC - direct current cardioversion; VKA - vitamin K antagonist; INR - international normalized ratio; NOAC - non vitamin K antagonist oral anticoagulant; LMWH - low molecular weight heparin; OD - odds ratio; $\mathrm{Cl}$ - confidence interval; RR- relative risk.

\section{Declarations}

\section{Ethics approval and consent to participate :}

The protocol of the study was approved by the local Ethics Committee and written informed consent was obtained from all participants

\section{Consent for publication:}

Not applicable

\section{Availability of data and materials:}

All data generated and analysed in this study are included in this published article and its supplementary information files 
Competing interests:

The authors declare that they have no competing interests

\section{Funding:}

Not applicable

\section{Authors contribution}

$\mathrm{KK}$ and MF conceived the concept of the study and contributed to the design of the research. KK, MR and MF were involved in data collection. KK, MF and LDS analyzed the data. All authors edited and approved the final version of the manuscript for publication

\section{Acknowledgements:}

Not applicable

\section{References}

1. Feinberg WM, Blackshear JL, Laupacis A, Kronmal R, Hart RG. Prevalence, age distribution, and gender of patients with atrial fibrillation. Analysis and implications. Arch Intern Med. 1995;155:46973.

2. Chugh SS, Roth GA, Gillum RF, et al. Global burden of atrial fibrillation in developed and developing nations. Glob Heart. 2014;9:113-9.

3. Bai Y, Wang YL, Shantsila A, et al. The global burden of atrial fibrillation and stroke: a systematic review of the Clinical epidemiology of atrial fibrillation in Asia. Chest. 2017;152:810-20.

4. Lip GY, Nieuwlaat R, Pisters R, et al. Refining clinical risk stratification for predicting stroke and thromboembolism in atrial fibrillation using a novel risk factor-based approach: The euro heart survey on atrial fibrillation. Chest. 2010;137:263-72.

5. Steinberg BA, Hellkamp AS, Lokhnygina Y, et al. Higher risk of death and stroke in patients with persistent vs. paroxysmal atrial fibrillation: results from the ROCKET-AF Trial. Eur Heart J. 2015;36:288-96.

6. Watson T, Shantsila E, Lip GY. Mechanisms of thrombogenesis in atrial fibrillation: Virchow's triad revisited. (10)Lancet. 2009; 373: 155-166.

7. Sikorska A, Baran J, Pilichowska-Paszkiet E, Sikora-Frąc M, Kryński T, Piotrowski R, Stec S, Zaborska $B$, Kułakowski P. Risk of left atrial appendage thrombus in patients scheduled for ablation for atrial fibrillation: Beyond the CHA2DS2VASc score. Pol Arch Med Wewnętrznej. 2015;125:921-8. 
8. Asher CR, Klein AL, et al. The ACUTE trial. Transesophageal echocardiography to guide electrical cardioversion in atrial fibrillation. Assessment of Cardioversion Using Transesophageal Echocardiography. Cleve Clin J Med. 2002 Sep;69(9):713-8.

9. Fatkin D, Scalia G, Jacobs N, Burstow D, Leung D, Walsh W, Feneley M. Accuracy of biplane transesophageal echocardiography in detecting left atrial thrombus. Am J Cardiol. 1996;77:321-3.

10. Manning WJ, Weintraub RM, Waksmonski CA, Haering JM, Rooney PS, Maslow AD, Johnson RG, Douglas PS. Accuracy of transesophageal echocardiography for identifying left atrial thrombi: a prospective, intraoperative study. Ann Intern Med. 1995;123:817-22.

11. Hart RG, Benavente $O$, McBride R, Pearce LA. Antithrombotic therapy to prevent stroke in patients with atrial fibrillation: a meta-analysis. Ann Intern Med. 1999;131:492-501.

12. Al-Saady NM, Obel OA, Camm AJ. Left atrial appendage: structure, function, and role in thromboembolism. Heart. 1999;82:547-54.

13. Kirchhof P. Benussi S. Kotecha D, et al. ESC Scientific Document Group 2016 ESC Guidelines for the management of atrial fibrillation developed in collaboration with EACTS. Eur Heart J. 2016;37(38):2893-962.

14. January CT, Wann LS, Alpert JS, et al. 2014 AHA/ACC/HRS Guideline for the Management of Patients With Atrial Fibrillation: Executive Summary A Report of the American College of Cardiology/American Heart Association Task Force on Practice Guidelines and the Heart Rhythm Society. J Am Coll Cardiol. 2014;64:2246-80.

15. Lip GY, Frison L, Halperin JL, et al. Identifying patients at high risk for stroke despite anticoagulation: a comparison of contemporary stroke risk stratification schemes in an anticoagulated atrial fibrillation cohort. Stroke J Cereb Circ. 2010;41:2731-8.

16. Wallace TW, Atwater BD, Daubert JP, et al. Prevalence and clinical characteristics associated with left atrial appendage thrombus in fully anticoagulated patients undergoing catheter-directed atrial fibrillation ablation. (1)J Cardiovasc Electrophysiol. 2010; 21: 849-852.

17. Zylla MM, Pohlmeier M, Hess A, et al. Prevalence of intracardiac thrombi under phenprocoumon, direct oral anticoagulants (dabigatran and rivaroxaban), and bridging therapy in patients with atrial fibrillation and flutter. (1)Am. J Cardiol. 2015;115:635-40.

18. Kosmalska K, Rzyman M, Fijałkowski M, et al. Usefulness of transesophageal echocardiography before cardioversion in atrial arrhythmias C Journal 2019; doi10.5603/CJ.a2019.0056.

19. Pepi M, Evangelista A, Nihoyannopoulos P, et al. Recommendations for echocardiography use in the diagnosis and management of cardiac sources of embolism: European Association of Echocardiography (EAE) (a registered branch of the ESC). Eur J Echocardiogr J Work Group Echocardiogram Eur Soc Cardiol. 2010;11:461-76.

20. Saric M, Armour AC, Arnaout MS, et al. Guidelines for the Use of Echocardiography in the Evaluation of a Cardiac Source of Embolism. J Am Soc Echocardiogr. 2016;29(1):1-42.

21. Flachskampf FA, Badano L, Daniel WG, et al. Recommendationsfortransoesophagealechocardiography: update 2010. Eur J Echocardiogr J Work 
Group EchocardiogrEurSocCardiol. 2010;11:557-76.

22. Fatkin D, Loupas T, Jacobs N, Feneley MP. Quantification of blood echo- genicity: evaluation of a semiquantitative method of grading spontaneous echo contrast. Ultrasound Med Biol. 1995;21:1191-8.

23. Fatkin D, Kelly RP, Feneley MP. Relations between left atrial appendage blood flow velocity, spontaneous echocardiographic contrast and thromboembolic risk in vivo. J Am Coll Cardiol. 1994;23:961-9.

24. Bernhardt $P$, Schmidt $H$, Hammerstingl C, et al. Patients with atrial fibrillation and dense spontaneous echo contrast at high risk a prospective and serial follow-up over 12 months with transesophageal echocardiography and cerebral magnetic resonance imaging. J Am Coll Cardiol. 2005;45:1807-12.

25. Scherr D, Dalal D, Chilukuri K, et al. Incidence and predictors of left atrial thrombus prior to catheter ablation of atrial fibrillation. J Cardiovasc Electrophysiol. 2009;20:379-84.

26. Lip GY, Hammerstingl C, Marin F, Cappato R, et al. Left atrial thrombus resolution in atrial fibrillation or flutter: Results of a prospective study with rivaroxaban (X-TRA) and a retrospective observational registry providing baseline data (CLOT-AF). Am Heart J. 2016 Aug;178:126-34.

27. Kapłon-Cieślicka A, Budnik M, Gawałko M, et al The rationale and design of the LATTEE registry - the first multicenter project on the Scientific Platform of the "Club 30" of the Polish Cardiac Society, Kardiol Pol 2019; 1078-1080.

\section{Figures}




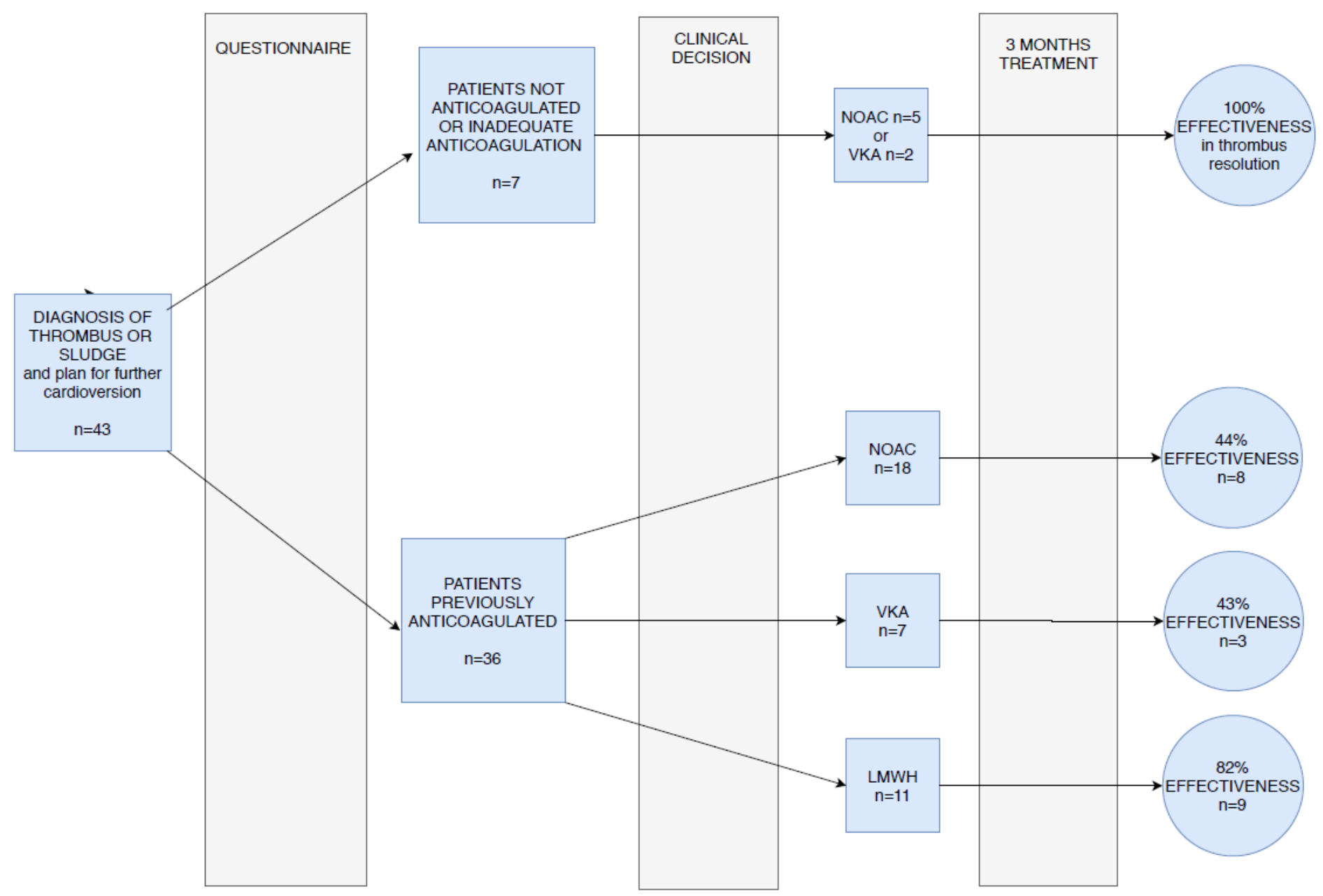

\section{Figure 1}

Graphic presentation of study decision tree, clinical course and treatment results. 